\title{
STUDENTS' ABILITY IN WRITING AN INTRODUCTORY PARAGRAPH OF ARGUMENTATIVE ESSAY
}

\author{
Rini Anita \\ Program Studi Tadris Bahasa Inggris, Jurusan Tarbiyah STAIN Batusangkar \\ Korespondensi: Perumahan Permata Rizano Blok E/12 Cubadak, Batusangkar \\ e-mail: karhine_anita@yahoo.com
}

\begin{abstract}
Writing well is not just an option for young people - it is necessary. They need writing skill as one of predicator of academic success and a basic requirement for participation in civic life. Seeing writing skill as one of important skill to be a well comprehended by young people, include students, writing appears as nightmare for struggling writers. Likewise, they often waste most of their time just for starting to write. This paper is intended to find out the students' ability in writing paragraph of argumentative essay particularly in writing the introductory paragraph, general statements and thesis statement.
\end{abstract}

Key Words: Ability, Introductory Paragraph, Argumentative Essay

\section{INTRODUCTION}

$\mathrm{N}$ owadays, writing skill is an essential thing to gain success in high school, college and job. It is urgently needed by students in order to pass their educational institution. Writing itself has become one of the tests in "Ujian Akhir Sekolah (UAS) beside other skills like reading and listening at senior high school. Whereas at university, they are required to write essays, tests, reports, paper and thesis during their studies. Likewise, writing skill is also necessary in writing formal application letters in applying for job or graduate training. In other words, writing has been identified as threshold skill for getting success in academic field as well as job section.

However, many students find writing more difficult than others. As Meyers (1992) says that it is more difficult to learn for native and non native speakers alike. It is because they have to demonstrate mastery of all writing elements such as content, organization, purposes, vocabulary, and the proper mechanic. In line with Meyers, Stephen and Vygotky (1986) in Marcus (1977) also say that writing is more difficult to learn that others since it should cover the topic more clearly and in great detail. At this point, the students can not use their facial expression, gestures, and mimic which help them to clarify meaning as what they do in speaking, for instance.

Considering about the difficulties of writing, English Department of State University of Padang (UNP) has made it as one of the compulsory subjects that should be mastered by the students. The Department provides several series of writing courses: Writing I (how to make an effective paragraph), writing II (How to make a good essay), and Writing III (How to write several types of essay) that are offered in different semester. 
When the students get in touch to write an essay, they will be given three important components like introduction, body and conclusion. From these three, introduction seems to be difficult to write on because the students have to attract the readers' interest to keep reading up to the end. Therefore introduction is not only as the first gateway into the paper, but also as a powerful device to evolve and prolong the interest initiated by the tittle so that the readers will be eager to read on. Anderson (2002) also claims that an introduction is the readers' first attention of the entire writing and to the writer's point of view. Readers of an essay often decide in the first paragraph whether they want to read further.

Additionally, by the time the students write the argumentative essay, their problems become complex. At the first side they have to fulfill all criteria of writing a good argumentative essay, and at the other side, they have to gain readers' attention to read the entire essay by presenting original, informative and eye-catching introduction indeed. It is in line to Mc Coy (1999). He claims that the beginning is usually the hardest part in writing. Mills (2002) also states that all writers even professional complain that the most difficult part of writing is getting started. Since, the first paragraph of an argumentative essay causes students most trouble yet carries the most importance, many students take extra time in writing it. This phenomenon also happened to English Department students of UNP. They tend to have difficulties in arranging an effective introductory paragraph such as starting the argumentative essay, attracting readers' interest, choosing the word to start, and so forth.

Based on the phenomenon mentioned before, some questions are aroused. How is the students' ability in writing an introductory paragraph of argumentative essay? How is students' ability in writing general statements of the introductory paragraph of argumentative essay? How is the students' ability in writing thesis statement of the introductory paragraph of argumentative essay?

\section{ARGUMENTATIVE ESSAY}

Generally, argumentative essay is a form of writing in which the writer argue for a certain idea and try to persuade readers to adopt the writer's point of view. Harvey (2003) also says that argumentative essay is the act of forming reasons, making orientations, drawing conclusions and applying them to the case in argument; the process of understanding propositions not known or admitted as true, from facts or principles known, admitted or proved true. In addition, argumentative essays present one side of an issue using evidence to convince the readers to draw the same conclusions as the writer. In short, argumentative essay has been defined as a well-structured and well-supported point of view on a topic that supported by reasons.

Similar to the other essay, argumentative essay also has three essential parts. The introductory paragraph that functions as attention getter for the readers then body paragraph where the writer actually proves the assertion at the end of the introduction and finally the concluding paragraph. It is in line with Jordan (1990) and Ozagac (2004) claim an academic essay, like argumentative essay, has three essential parts. The first paragraph of an essay is an introductory paragraph. It consists of general to specific statements and a thesis statement. The following paragraph is called body paragraph. It contains as many as paragraph as necessary to explain the controlling idea in the thesis statement in a logical sequence. The last paragraph of the essay is concluding paragraph which give the readers the 
conclusion or the summary of the essay and the writer's final comments.

\section{AN INTRODUCTORY PARAG- RAPH OF ARGUMENTATIVE ESSAY}

In most types of writing, the first thing that a writer does is to write the introductory paragraph, which introduces the subject to be dealt with the readers. It is the place where the essay has to make a good impression, informs the readers what is to come and encourages them to read further. It should convince the readers that the writer offers an original approach to an interesting topic in a lively style. As discussed before, it is important to write an introductory paragraph that will convince the readers that the essay is worth reading.

Generally, the introductory paragraph has two central parts (Djuliarso: 2000). First, general statements that gives background information on the topic and gets the readers interested in the topic. The second one is the thesis statement. As the most important sentence in the introductory paragraph, it states the main topic lists the subdivisions of the topic, indicates the method of the entire paper and usually the last sentence in the introductory paragraph. Mills (2002) states a general statement is sentences that give background information on the subject and gradually lead to the readers in the specific topic. Moreover the general statements should introduce the topic of the essay and give background information on the topic. DeSoto (1999) adds that the general statements have four main characteristics. First, it introduces the topic of the essay. Second, it gives background information of the topic. Third, it starts with general comments about the subject to attract readers' attention (attention grabber). It is challenging claim or surprising story catch the readers' attention.

There are some techniques in writing the attention grabber. They are (1) anecdote: it is a story that illustrates a point. The anecdote will present a brief dramatic scene or part of an interesting or humorous story. The anecdote should be short, straight to the point and relevant to the topic. (2) Quotation: the writer may have come across a statement in a play, novel, poem, newspaper or magazine that captures and um up the ideas better than the writer can. A quotation does not have to be from great poet or prose writer, it may be from anyone who I qualified to speak about the writer's topic and main idea. (3) Series of questions: beginning a written composition with a series of engaging, though-provoking question(s) starts the readers thinking right away. The question (or series questions) is a device to attract the readers' participation and actively engages the readers' minds. (4) build up the background: sometimes the most forceful way to lead up to the thesis statement is to present background information and steadily build toward the thesis.

Thesis statement, on the other hand, is a sentence (or sentences) claim in the end of the form of a clear statement at the beginning of the essay. It is also a very specific statement that covers only what the writer wants to discuss in the essay and supported with specific evidence. Fournier (2004) says that thesis statement is a deliberate affirmation expressing an opinion, an attitude or original idea on the topic or a piece of literature. A thesis statement generally consists of two parts (Guilford: 1996). The first one is the topic and then analysis, explanation(s) or ascertain(s) that the writer making about the topic. Anderson (2002) states that an effective thesis is the foundation of the entire essay which has some criteria like it should be potentially interesting to the 
readers, should be as specific as possible, should limit and focus the topic in manageable way. While Djuliarso (2002) says that a successful thesis statement at least has four main characteristics as follow: it should be a complete sentence, it should be unifiedexpress only one main idea, it should be restricted-the central idea is narrowed from general to specific tone, it should be specific-not using vague words. To sum up, the characteristics of good general statements are it should introduce the topic of the essay, give background information of the topic, start with a very general comments about the subject to attract readers' attention (attention grabber) and finally lead to the readers in the specific topic of the essay. While the characteristics of thesis statement are it should be complete sentence, unified, restricted, specific, contestable, provocative, substantive, not a fact, personal experience and a question.

\section{RESEARCH METHODOLOGY}

The design of the research was descriptive since it only described the students' ability in writing an introductory paragraph of argumentative essay concerning the general statements and thesis statement as the crucial parts in the introductory paragraph. The population of the research was the second year students of English department of UNP who enrolled in the year of 2004-2005. The researcher chose them because they had passed their writing classes. Consequently, they were able to write the good quality of essay particularly in writing an effective introductory paragraph. In order to get the sample, the researcher applied cluster sampling technique in which the group is randomly selected. Among four classes of regular and non regular program, 25 students were selected as the sample of the research. The instrument of the research was the writing test which has four given topics: Young Marriage, The Death Penalty in Indonesia, Students Exchange Program and Sex Education at School. Here, the students were asked to write 500 words in 1-2 hours time allocation.

In analyzing the data, the researches used criteria of an effective general statements and thesis statement discussed earlier. Since the instrumentation was writing test, the subjectivity might appear in analyzing the test. In order to minimize it, the researcher was helped by two qualified writing scorer. Indeed, the researcher used analytic score proposed by Cohen (1994). It I used for separate scales in which criteria were divided into five behavioral levels indicated by the scale 1 to 5 as shown by the table below:

Table 1. Scoring Rubric

\begin{tabular}{cl}
\hline 5 & Writing is excellent and the students can fulfill all criteria well \\
\hline 4 & Writing is good and the students are only weak on one of the criteria \\
\hline 3 & Writing is average and the students are weak on some criteria \\
\hline 2 & Writing is poor and the students are weak on almost criteria \\
\hline 1 & Writing is very poor and the students weak on all criteria \\
\hline
\end{tabular}

In addition, the researcher also used percentage to show the ability of the students in writing an introductory paragraph of argumentative essay related to general statements and thesis statement. 
THE STUDENTS' ABILITY IN WRITING GENERAL STATEMENTS OF AN INTRODUCTORY PARAGRAPH OF ARGUMENTATIVE ESSAY

The data showed from 25 students, 8 students wrote the topic of Young Marriage, 4 students wrote the topic of Death Penalty in Indonesia, 6 students wrote the topic of Students Exchange Program and 7 students wrote the topic of Sex Education at School. From 25 students only one paper could no be analyzed because the writer did not write argumentative essay but an explanation essay. Two writing lecturers as the scorer and the researcher herself analyzed the data by using the same criteria discussed before.

From the average scores of the three scores, it was found that the ability of the students in writing general statements of an introductory paragraph of argumentative essay was good; It was about ten students $(41.67 \%)$ out of 24 students. While in writing thesis statement, the ability of the students in writing thesis statement of an introductory paragraph of argumentative essay was average; It was about nine students $(37.5 \%)$ out of 24 students.

Question 1. How is the student ability in writing general statements of an introductory paragraph of argumentative essay?

The ability in writing the general statements was analyzed based on four criteria as follow:

1. It introduces the topic of the essay.

Every introductory paragraph has to introduce the topic to the readers. From 24 students, 21 students introduced the topic of the essay clearly at the beginning of their argumentative essay. It means that they are excellent in introducing the topic of the essay with some indication of its interest or importance and a clear definition of the boundaries of the subject area. On the other hand, three students did not introduce the topic of the argumentative essay clearly.

2. It gives background information of the topic.

General background or background information is the place for the writer to set the science for their readers and introduces the main idea of the essay. From 24 students, 17 students were successful in giving background information of the topic by starting it with grand or general opening statements at their introductory paragraph. While 7 students failed to give background information of the topic of the argumentative essay.

3. It starts with general comments about the subject to attract the readers' attention (Attention Grabber).

As discussed earlier, an introductory paragraph should be design to attract the readers' interest and give them an idea of the essay's focus. It is called as attention grabber. There are some techniques in writing the attention grabber like begin with anecdote, quotation, question or series of questions, build up common ground or background information and so forth. From 24 students, all students used attention grabber. 1 student wrote introductory paragraph with a quotation, 3 students wrote it with question(s), 20 students used background information as the attention grabber of the introductory paragraph.

4. It leads the readers to the specific topic of the essay.

Good general statements of an introductory paragraph also have to acquire the last criterion that is leading the readers to the specific topic of the essay. The writer brings the readers from the broad topic in the attention grabber 
to the specific topic of the essay. From 24 students, 18 students lead the readers to the specific topic and 6 students were failed.

\section{Question 2. How is the student ability in writing thesis statement of an introductory paragraph of argumentative essay?}

The ability in writing the thesis statement of the introductory paragraph of argumentative essay was analyzed based on eight criteria as below:

\section{It should be a complete sentence.}

A good thesis statement should be a complete sentence. A sentence is an independent group of words, which is express a complete thought that must contain a subject (expressed or implied) and a predicate. From 24 students, 19 students wrote the thesis statement in a complete sentence and 5 students did not write the thesis statement.

\section{It should be unified.}

The thesis statement expresses only one central idea. It cannot be in the form of a compound sentence since it contains more than one main idea. From 24 students, 15 students wrote the unified thesis statement. While 7 students were failed. Most of them write compound/complex sentences which indicate the thesis statement had more than one idea.

\section{It should be restricted.}

Restricted means the central idea in the thesis statement is narrowed down from a general topic to a manageable aspect of that topic. From 24 students, 14 students wrote the restricted statement while 10 students did not write it.

\section{It should be specific.}

Specific means the language is not vague and imprecise so that the writer expresses a clear direction in which to take the readers' attention. From 24 students, 13 students wrote the thesis statement in specific language but not for 11 students. They failed because they did not narrow the subject to more specific ones and they did not identify the specific topic as well.

5. It should be contestable.

The thesis statement should be contestable or arguable. Contestable or arguable means the idea can be discussed and debated. It is not either completely obvious or constitutes knowledge on the subject. From 24 students, 18 students wrote the contestable thesis statement and the rest of them (6 students) did not write the contestable one. The students who were failed in writing contestable thesis statement did not give an arguable point to their thesis statement.

6. It should be provocative.

Provocative means taking a stand and justifying the discussion the writer will present. From 24 students, 18 students wrote the provocative thesis statement and 6 students were failed. The students failed because they tend to write contrasting ideas in their thesis statement. It makes the thesis statement less provocative to the readers.

7. It should be substantive.

The thesis statement should be substantive. It should do more than introducing topic or announcing what the paper will discuss. The thesis should attract the readers' interest by briefly stating the claim that the paper will focus on. From 24 students, 18 students wrote the substantive statement and 6 students were failed. They neither attract readers' attention nor guide the readers the focus of the essay in their statement.

8. It should not a fact, personal experience and a question.

From 24 students, almost all students wrote the criterion, only 5 students did not write the thesis statement. The students only gave background information to the readers. 
Other finding that is not related to the research question but it was found by the researcher is most of the students are interested in writing the common topics among four topics provided by the researcher such as Young Marriage (8 students), Sex Education at School (7 students), and Students Exchange Program (6 students). While there were only 4 students out of 24 students wrote the fourth topic: The Death Penalty at Indonesia. Due to that, the researcher assumed that the students are less interested in choosing the fourth topic because of lack knowledge, does not have any ideas in writing the topic or afraid in discussing the topic.

\section{CONCLUSION}

The present research is meant to describe the ability of the second year of English department students of UNP in writing an effective introductory

\section{REFERENCES}

Anderson, Marylin. 2002. Keys to Successful Writing: Unlocking the Writer within. USA: Addison Wesley Longman, Inc.

Bloggs. 2004. The Intorductory Paragraph.

http://www.English.perdu.edu/OW LRetrieved on Saturday, April $22^{\text {nd }}$ 2006.

Carino, Peter. 1991. Basic Writing: a First Course. USA: Indiana State University.

Cohen, Andrew D. 1994. Assesing Language Ability in the Classroom: Second Edition. USA: Heinle and Heinle Publishers.

Djuliarso. 2000. General English Advanced: The World 'Home'. Jakarta: PT. Siwi Bakti Darma

Harvey, Michael. 2003. The Art of Argumentative Essay. Nuts and paragraph of argumentative essay. An effective introductory paragraph consists of two essential parts; general statements and thesis statement. It finds that they are good in writing the general statements and average in writing thesis statement. However there are admittedly still some limitations. The first limitation relates to the data source. The sample of this research is relatively small (24 students) from one class. Therefore, it could not fully represent the whole population of the students from 8 classes. In other word, the findings cannot be generalized to all students in the second year of UNP in academic year 2004/2005. The second limitation is about the time when they had the writing test. They did it as soon as their class was over. It is considered they were in tense although the researcher has set convenience atmosphere in the classroom.

Botts of College Writing: Hacket Publishing.

Henley, Jennifer Jordan. 1988. A Brief Guide to Writing Argumentative Essay. http://www.rscc.cc.tn.us/OWL retrieved on Tuesday, January 31 2006.

Jordan, R.R. 1990. Academic Writing Course. London: Collins \& Glasgow.

Kies, Daniel. 1995. Argumentative Essay. www.essayinfo.com. retrieved on Saturday, April $9^{\text {th }}$ 2006.

Marcus, Marie. 1977. Diagnostic Teaching of the Language Arts. Canada: John Wiley and Sons, Inc.

Mc Coy, Sam. 1999. Writing an Essay Introduction. http://www.leo.stcloudstate.edu/ac 
136 Ta'dib, Volume 15, No. 2 (Desember 2012)

awrite/into.html retrieved on Mills. 2000. Writing Academic English. Tuesday, January $31^{\text {st }} 2006 . \quad$ Addison Wesley Publishing Meyers, L Bensel. 1992. Rhetoric for Academic Reasoning. USA: Harper Collins Publishers, Inc. Company.

Ozagac, Oya. 2004. Introducing Paragraphs and Thesis Statement. Pearson Education, Inc.

Indeks

Ability ................................... 189, 135

Paragraph

189,135

Essay $189,135,136$

students .... 189, 130, 132, 133, 134, 135 